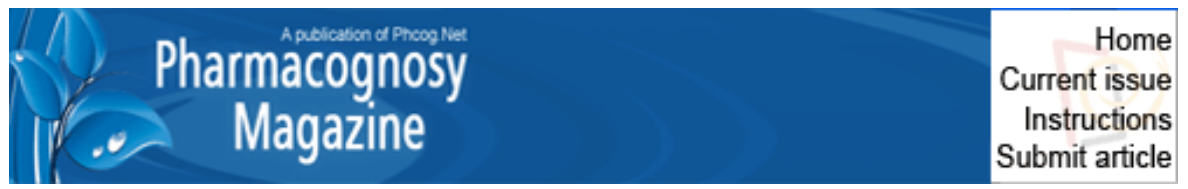

\title{
Evaluation of Antiplasmodial activity of extracts and constituents from Ampelozizyphus amazonicus
}

\author{
Dominique F. M. do Carmo, Ana Claudia F. Amaral, ${ }^{1}$ Marta Machado, ${ }^{2}$ Dinora Lopes,${ }^{2}$ Aurea Echevarria, ${ }^{3}$ \\ Virgílio E. Rosário, ${ }^{2}$ and Jefferson Rocha de A. Silva \\ Department of Chemistry, Chromatography Laboratory, Federal University of Amazonas (UFAM), Rodrigo Otavio Avenue, 3000, Academic \\ Campus, 69077-000, Manaus, Amazonas, Brazil \\ ${ }^{1}$ Department of Natural Products, Medicinal Plants and Derivatives Laboratory, Farmanguinhos, Oswaldo Cruz Foundation (FIOCRUZ), \\ Sizenando Nabuco Street, 100, Manguinhos, 21041-250, Brazil \\ ${ }^{2}$ Parasitology Unit, Center of Studies on Malaria and Other Tropical Diseases, LA, Institute Hygiene and Tropical Medicine from the New \\ University of Lisbon, Junqueira street, 100, 1349-008 Lisboa, Portugal, Brazil \\ ${ }^{3}$ Department of Chemistry, Federal Rural University of Rio de Janeiro (UFRRJ) Km 47, Seropedica, 23851970, Rio de Janeiro, RJ, Brazil \\ Address for correspondence: Dr. Jefferson Rocha de A. Silva, Department of Chemistry, Chromatography Laboratory, Federal University \\ of Amazonas (UFAM), Rodrigo Otavio Avenue, 3000, Academic Campus, 69077-000, Manaus, Amazonas, Brazil. E-mail: \\ jucha 01@yahoo.com.br
}

Received 2014 Sep 25; Revised 2014 Nov 14; Accepted 2015 Sep 24.

Copyright : () Pharmacognosy Magazine

This is an open access article distributed under the terms of the Creative Commons Attribution NonCommercial ShareAlike 3.0 License, which allows others to remix, tweak, and build upon the work non commercially, as long as the author is credited and the new creations are licensed under the identical terms.

\section{Background:}

Ampelozizyphus amazonicus Ducke, a plant that is widely used by the population of the Amazonian region to prevent and treat malaria, was investigated in this work, which describes, for the first time, the antiplasmodial activity of its extracts and associates this activity with its isolated constituents.

\section{Methods:}

Different extracts with solvents of increasing polarity (hexane, chloroform, ethanol, and water) were obtained of the root bark. This procedure resulted in extracts that were characterized for their constituents. The cytotoxicity and activity of the extracts against Plasmodium berghei (schizontocidal activity, liver stage) and Plasmodium falciparum (3D7 and Dd2 strains, erythrocyte stage) were assessed in vitro.

\section{Results:}

Of the four extracts assayed against $P$. berghei, the chloroform extract showed the greatest activity, with an inhibitory concentration $50 \%\left(\mathrm{IC}_{50}\right)$ value of $30.1 \mu \mathrm{g} / \mathrm{mL}$, followed by the aqueous extract $\left(\mathrm{IC}_{50}=39.9\right.$ $\mu \mathrm{g} / \mathrm{mL}$ ). The chloroform extract exhibited the highest antiplasmodial activity in the erythrocyte stage of $P$. falciparum, with an $\mathrm{IC}_{50}$ value lower than $15 \mu \mathrm{g} / \mathrm{mL}$. Fractionation of this more active extract led to the isolation and elucidation of pentacyclic triterpenes, lupeol, betulin and betulinic acid, which showed antiplasmodial activities with $\mathrm{IC}_{50}$ values ranging from 5.6 to $80.30 \mu \mathrm{M}$. The most active of these, betulinic acid, was further quantified in the extracts by high-performance liquid chromatographyphotodiode array detector analyzes. The higher amount was found in the chloroform extract, which was the most active one against $P$. falciparum.

\section{Conclusion:}


The results obtained in this work may partly explain the popular intake of A. amazonicusas an antimalarial remedy in the Amazon region.

Keywords: Ampelozyziphus amazonicus, antimalarial activity, rhamnaceae, triterpenes

Malaria is a major parasitic health problem in tropical and subtropical regions, caused by infection with Plasmodium species and transmitted by Anopheles mosquitoes. It is endemic in 106 countries and is responsible for about 216 million clinical cases and about 655,000 deaths in 2010.[1]

Five species of Plasmodium can cause human malaria: Plasmodium falciparum, Plasmodium vivax, Plasmodium malariae, Plasmodium ovale and Plasmodium kwnolesi Cox-Singh; Singh. Of these, $P$. falciparum is the most prevalent and lethal; when left untreated, it can lead to fatal malaria.[ㄹ] Until recently, treatments against $P$. falciparum relied on chloroquine and sulfadoxine-pyrimethamine. However, resistance to these drugs led the World Health Organization to recommend the use of artemisinin combination therapy (ACT), [3] in which artemisinin derivatives, some new fast-acting antimalarial agents, are used in combination with another antimalarial in order to reduce the chances of $P$. falciparum becoming resistant to either drug. Unfortunately, clinical resistance to ACT has been reported in the Cambodia-Thailand border region, $[\underline{3}, \underline{4}]$ which suggests that $P$. falciparum parasites have already developed the ability to grow in the presence of these antimalarials, and strongly indicates the need for further research into new ones.[]]

Plants used in traditional medicine may offer a promising source of substances with antimalarial activity. An approach to the identification of antimalarial drug candidates is to search for compounds from plants that are used in folk medicine to prevent or cure malaria. Thus, it is worth documenting the ethnobotanical information and testing the antiplasmodial activity of plant extracts. The species Ampelozizyphus amazonicus Ducke is a strong candidate from the Amazon region. This species of the rhamnaceae family, known locally as cerveja de indio (Indian beer), among other common names, is a hardy liana distributed in South America and found in the Amazon region of Brazil, Venezuela, Colombia, Peru, and also Ecuador. In Brazil, it is found in forests of the States of Amazonas, Pará, and Roraima.[6]

There are different preparations reported for this species;[]] the most widespread one is a mixture of $A$. amazonicus root bark and water used as a preparation for malaria, and usually taken before bathing.[] $]$ This preparation acquires a yellow color and the appearance of frothy beer, but the foam is removed before drinking. According to Oliveira et al. (2011),[7] A. amazonicus is able to prevent and treat malaria. Other uses are attributed to this species, such as treatment of fever,[9] anti-inflammatory uses, and as an antidote for snake venoms.[]

In the last decade, some pharmacological studies have demonstrated the trypanocidal activity of the crude extracts, fractions and isolated compounds of $A$. amazonicus stems against the trypomastigote forms of Trypanosoma cruzi [10] and also the in vitro and in vivo prophylactic activity of the crude ethanol extract of A. amazonicus roots against Plasmodium gallinaceum[] $]$ and on preerythrocytic development of Plasmodium berghei,[11] respectively. Furthermore, there are published reports of the diuretic activity of the saponins mixture of the roots of this species,[12] showing an activity that had not been previously reported. Although there have been some published reports about this species,[6] the active substances of A. amazonicus have not yet been identified, and no reports exist on its activity against the erythrocytic development of Plasmodium species/strains. Only crude extracts were tested and presented no activity in the assay models used by the authors.[] $]$

A recent review describes the few phytochemical studies published on this species, which report the presence of triterpenoids, steroids, and saponins.[6] The aim of this work is to evaluate the antiplasmodial activity of the extracts obtained from A. amazonicus root barks, prepared according to their popular use, and with solvents of different polarities, and the chromatographic fractionation of the most active ones. The study includes assays against the liver stage of $P$. berghei and against the asexual blood stages in chloroquine susceptible and resistant $P$. falciparum strains. It also describes the active constituents associated with this activity and the quantification of betulinic acid in the extracts. 


\section{Chemical analysis}

Nuclear magnetic resonance (NMR) spectra were run on a Bruker 400 or $500 \mathrm{MHz}\left({ }^{1} \mathrm{H}: 400 ; 500 \mathrm{MHz}\right.$; $\left.{ }^{13} \mathrm{C}: 100 ; 125 \mathrm{MHz}\right)$ spectrometer in solvents $\left(\mathrm{CDCl}_{3}\right.$ and $\left.\mathrm{CD}_{3} \mathrm{OD}\right)$ with chemical shifts reported in parts per million relative to the residual solvent peaks.

Analytical high-performance liquid chromatography (HPLC) analysis was performed on a Shimadzu LC-8 Avp gradient chromatograph equipped with two LC-8Avp pumps, controlled by an interface module and an automatic injector, and an SPD-M10 Avp photodiode array detector (PAD) was used for the peak purity test and analysis of compounds. The solvents were filtered using a Millipore system, and chromatographic separation was carried out on a C18 column $(150 \mathrm{~mm} \times 4.6 \mathrm{~mm}, 5 \mu \mathrm{m}$; Shimpack). HPLC grade solvents and Milli-q water were used in this study, and all the chromatographic experiments were obtained under isocratic conditions at room temperature.

\section{Plant}

The roots of A. amazonicus were collected in Ducke Reserve (Amazonas State, Brazil). A voucher specimen (191532) is deposited at INPA (Instituto Nacional de Pesquisa da Amazônia), in the city of Manaus, State of Amazonas, Brazil.

\section{Extraction and isolation}

The air dried root bark ( $250 \mathrm{~g}$ ) of A. amazonicus was milled into a powder, and then extracted successively with hexane, chloroform, and ethanol. The aqueous extract was prepared according to the popular use.[6] The organic solvents were evaporated using a rotary evaporator, and the aqueous extract was lyophilized.

The active chloroform extract of the root bark ( $790 \mathrm{~g}$ ) was submitted to flash chromatography, using silica gel (70-230 mesh, $60 \AA$, Aldrich, $140 \mathrm{~g}$ ) with hexane/ethyl acetate 9:1, hexane/ethyl acetate 3:7, ethyl acetate $100 \%$ and $\mathrm{MeOH} 100 \%$ as eluents, yielding three fractions after thin layer chromatography analysis. Among these fractions, the only active fraction (392 mg) was subjected to chromatography on silica gel (230-400 mesh, Merck), and eluted with a step gradient of increasing ethyl acetate percentage in hexane. This procedure resulted in compounds $1(8.4 \mathrm{mg}), 2(187.6 \mathrm{mg}), 3(6.3 \mathrm{mg})$ and $4(25.4 \mathrm{mg})$.

Lupeol (1) - Colorless needles $\left(\mathrm{CH}_{2} \mathrm{Cl}_{2}-\right.$ hexane); $\mathrm{mp}=211^{\circ} \mathrm{C}$; identified by comparison with literature data (mp, MS, ${ }^{1} \mathrm{H}$ and $\left.{ }^{13} \mathrm{C} \mathrm{NMR}, \mathrm{CDCl}_{3}\right)$.[13]

Betulinic acid (2) was crystallized from $\mathrm{MeOH}$ as white crystals $\left(\mathrm{mp} 297^{\circ} \mathrm{C}\right)$ and characterized by spectral MS and NMR $\left(\mathrm{CD}_{3} \mathrm{OD}\right)$ analyzes and comparison with the literature data.[14]

Betulin (3): White crystalline $\left(\mathrm{CHCl}_{3}\right) ; \mathrm{mp} 259^{\circ} \mathrm{C}$. The identification was made by MS and $\mathrm{NMR}\left(\mathrm{CDCl}_{3}\right)$ analyzes and comparison with the literature data.[15]

Melaleucic acid (4) was crystallized from $\mathrm{MeOH}$ (white crystals, $\mathrm{mp} 320^{\circ} \mathrm{C}$ ). The spectroscopic data NMR $\left(\mathrm{CD}_{3} \mathrm{OD}\right)$ were in accordance with the literature data. $[\underline{16}, \underline{17}]$

\section{Quantification of betulinic acid by high-performance liquid chromatography}

Analytical HPLC analysis was performed on a Shimadzu LC-8 Avp gradient chromatography system. Stock solutions of hexane and chloroform extracts and isolated betulinic acid were prepared in methanol and sonicated in an ultrasonic bath for $30 \mathrm{~min}$. The final concentration of each sample was $1 \mathrm{mg} / \mathrm{mL}$. An aliquot of $20 \mu \mathrm{L}$ was injected five times on the HPLC column (Shimadzu XR, ODS $50 \mathrm{~mm} \times 2 \mathrm{~mm}, 5$ $\mu \mathrm{m})$, and the elution was carried out with water: Acetonitrile 30:70 (\%, v/v) at a flow-rate of $1.0 \mathrm{~mL} / \mathrm{min}$. The samples were monitored at $210 \mathrm{~nm}$, and each concentration was injected five times. The calibration solution contained this standard in the range of $15.62-1000 \mu \mathrm{g} / \mathrm{mL}$. The curve was plotted using the area average and betulinic acid concentration $(\mu \mathrm{g} / \mathrm{mL})$. All solvents were HPLC-UV grade (Tedia Brazil).

\section{Linearity and detection limit}

For the evaluation of the detection limit, a concentration sequence of betulinic acid was obtained by diluting the standard solution from 1000 to $0.24 \mu \mathrm{g} / \mathrm{mL}$. The limit of detection was $0.52 \mu \mathrm{g} / \mathrm{mL}$ and was 
calculated based on three times of signal-to-noise ratio $(\mathrm{S} / \mathrm{N}=3)$. Solutions of betulinic acid, at five different concentrations, were prepared to check the linearity, in the same volumetric flasks, using their respective stock solutions. The calibration curves were drawn in the concentration range of 500-15.65 $\mu \mathrm{g} / \mathrm{mL}$. The spectrum was measured three times for each concentration. The equation for the calibration curve was $y=3424 x+10340$ and the correlation coefficient of the calibration plot was 0.999 , indicating good linearity.

\section{Repeatability}

One of the concentrations $(250 \mu \mathrm{g} / \mathrm{mL})$ was used to obtain repeatability. Intra-day and inter-day repeatability experiments were conducted. The data used to calculate relative standard deviation (RSD) of inter-day repeatability were the areas of four injections over a period of three days. The data for intra-day repeatability were the areas of five injections on the same day. The RSD values were $3.19 \%$ for intra-day and $1.47 \%$ for inter-day.

\section{In vitro antimalarial liver stage assay}

Female Balb/c strain mice weighting 20-25 $\mathrm{g}$ and the ANKA clone of $P$. berghei were used throughout the experiments. To produce sporozoites, 4-7-day-old, nulliparous Anopheles stephensi (approximately 250 mosquitoes) were fed on gametocytemic mice and maintained thereafter at $21^{\circ} \mathrm{C}$ for $18-21$ days. The parasite infection status within the mosquito cages was monitored at day 8 by examining 5-10 mosquito midguts for the presence of oocysts (infection ratio).

On the $19^{\text {th }}$ day, the salivary glands were dissected for the detection and isolation of sporozoites and a subsequent infection of Hep G2 cells. Briefly, HepG2 cells $\left(15 \times 10^{4}\right.$ cells $\left./ \mathrm{mL}\right)$ were plated in eightchamber plastic Lab-Teck slides for $24 \mathrm{~h}$ prior to infection with $10 \times 10^{4}$ sporozoites $/ \mathrm{mL}$. The sporozoites were freshly obtained through disruption of the salivary glands of infected female $A$. stephensi mosquitoes and were added to each well. After $3 \mathrm{~h}$ at $37^{\circ} \mathrm{C}$, the cultures were washed and further incubated with extracts, for $48 \mathrm{~h}$ after infection. Primaquine was used as antimalarial control drug. The inhibition of parasite development was measured through the immunofluorescent assay (IFA). Afterward, $48 \mathrm{~h}$ cells were washed with PBS, fixed with methanol and incubated with a $100 \mu 1$ mixture of monoclonal antibody i72 $(20 \mu \mathrm{l})$ and phosphate-buffered-saline (PBS) $(980 \mu \mathrm{l})$ for $30 \mathrm{~min}$ to $1 \mathrm{~h}$, in a humid chamber.[18] The wells were then washed with $300 \mu 1$ PBS and $100 \mu 1$ mixture of GAMIg / FITC and PBS for another 30 min, under the same conditions; glass slides were prepared with a 1:1 glycerol/PBS solution. The number of parasites was then determined by fluorescence microscopy. The dose-response curves of the drugs were determined compared to control (without drug) preparation wells. The concentration that inhibits $50 \%$ of parasite development $\left(\mathrm{IC}_{50}\right.$ ) was determined by nonlinear regression analyzes using the GraphPad Prism for windows version 5.01, GraphPad Software, Inc.

\section{In vitro antimalarial activity in erythrocytic stages}

Human malaria parasites were cultured as previously described by,[19] with minor modifications. Briefiy, chloroquine-sensitive (3D7) and chloroquine resistant (Dd2) P. falciparum strains were maintained in continuous cultures in fresh human erythrocyte in RPMI 1640 medium (Gibco) containing 25 mM HEPES (Sigma) and $6.8 \mathrm{mM}$ hypoxanthine (Sigma) supplemented with 10\% AlbuMAX II (Invitrogen). The culture medium was changed daily, and the culture was kept at $37^{\circ} \mathrm{C}$ in a mixture of $5 \% \mathrm{O}_{2}, 3-5 \% \mathrm{CO}_{2}$, and $\mathrm{N}_{2}$ environment. The in vitro evaluation of antimalarial activity in the erythrocyte stage of $P$. falciparum was performed with synchronized cultures (with sorbitol 5\%) in ring-stage parasites, under different concentrations of the studied extracts and fractions, using the same culture without additional compounds as control. The antimalarial activity of the compounds was determined by a fluorometric assay using SYBR Green;[20] briefly, stock solutions of the samples were prepared in DMSO, and were diluted to give a series of concentrations ranging from 3.9 to $250 \mu \mathrm{g} / \mathrm{mL}$. $50 \mu \mathrm{L}$ of each test concentration, together with $50 \mu \mathrm{l}$ of a $1 \%$ red blood parasitized cell suspension with ring stages and $2 \%$ hematocrit, were distributed, in triplicate, into each of the 96 -well plates and incubated for $48 \mathrm{~h}$ at $37^{\circ} \mathrm{C}$. Next, $100 \mu \mathrm{l}$ of lysis buffer (Tris $20 \mathrm{mM}$; pH 7.5, EDTA $5 \mathrm{mM}$, saponin - 0.008\%; wt/v, Triton X-100-0.08\%; v/v) containing SYBR Green at a concentration of $2 \mathrm{mg} / \mathrm{mL}$ were added to each microplate well. The plates were covered, mixed and incubated in the dark at room temperature for $1 \mathrm{~h}$. The fluorescence emitted was 
measured in multiwell plate reader, Anthos venyth 3100 (Alfagene) with excitation and emission wavelengths of $485 \mathrm{~nm}$ and $535 \mathrm{~nm}$, respectively. Values were expressed in relative fluorescence units. Analysis of the results obtained and $\mathrm{IC}_{50}$ determination were performed with HN-NonLin V1.05 Beta software.[21]

The conventional microtest method (Mark III),[22] based on evaluation of parasite development by optical microscopy, were used as control of the selected fluorimetric method.

The selectivity index (SI), corresponding to the ratio between cytotoxic and antiparasitic activities, was calculated as follows:

SI Plasmodium $=\left(\mathrm{IC}_{50}\right.$ HepG2 $) /\left(\mathrm{IC}_{50}\right.$ Plasmodium $)$.

\section{Antimalarial activity of extracts and fractions}

An initial screening was performed on the four extracts listed in Table 1, in order to investigate the cytotoxicity, in vitro antimalarial activity on the hepatic pre-erythrocytic stage of $P$. berghei and also, against 3D7 chloroquine-sensitive and $\mathrm{Dd} 2$ chloroquine-resistant strains of $P$. falciparum. $\mathrm{IC}_{50}$ values were calculated from the set of seven concentrations tested for each extract.

Concerning the in vitro antimalarial activity against the liver stage of $P$. berghei (in Hep G2 cells), two of the four extracts tested [Table 1] revealed good hepatic schizontocidal activity, with only the chloroform extract of the root back having concentration below the respective $\mathrm{IC}_{50}$ value for cytotoxicity. This latter extract, CRBAa, showed the highest activity with an $\mathrm{IC}_{50}$ value of $30.1 \mu \mathrm{g} / \mathrm{mL}$, followed by the aqueous extract of the root bark (AqRBAa, $\mathrm{IC}_{50}=39.9 \mu \mathrm{g} / \mathrm{mL}$ ). The result obtained for the aqueous extract of the root bark is comparable to that obtained by Andrade-Neto et al. (2008)[11] who tested the ethanol extract of the root $(28.8 \mu \mathrm{g} / \mathrm{mL})$. Despite this similarity, this aqueous extract showed a higher cytotoxicity $(17.50$ $\mu \mathrm{g} / \mathrm{mL}$ ) probably due to the great amount of saponins in this extract,[6] when compared to the other extracts analyzed.

The in vitro effect of the four extracts on the erythrocyte stage of $P$. falciparum was also tested, with interesting results. As shown in Table 1, all the studied extracts presented weak activity, with the exception of chloroform extract of $A$. amazonicus root bark (CRBAa), which exhibited the best antimalarial activity against 3D7 and Dd2 strains of P. falciparum, with $\mathrm{IC}_{50}$ values of 13.79 and $14.63 \mu \mathrm{g} / \mathrm{mL}$, respectively.

The SI values observed for the most active extract, CRBAa, showed low selectivity $(<5.0)$; however, these values showed better selectivity for P. falciparum among the other studied extracts, with SI from 0.26 to 1.81 [Table 1].

This result was surprising because so far, the studies performed to verify the activity of the root extracts on the blood stage of the cycle of malaria have been negative.[조,11] In addition, these data showed the importance of extract preparation with solvents of different polarities, with fewer constituents than a crude ethanol or aqueous extract, for optimum evaluation of the pharmacological activity associated with the popular use of any botanical species. In this context, using the methodology for preparation of the extracts described above, results hitherto not described for A. amazonicus were observed, such as active extracts enriched with a mixture of closely related substances of similar polarities, diluted in a less complex matrix of phytocompounds.

In order to identify the constituents responsible for the activity observed, the CRBAa extract was fractionated as mentioned in materials and methods, and the isolated compounds were tested against 3D7 chloroquine-sensitive and Dd2 chloroquine-resistant $P$. falciparum strains. The structures of lupeol, betulinic acid, betulin and melaleucic acid were elucidated based on NMR and MS analyzes, and by comparison with the literature data. Previous studies mentioned the presence of pentacyclic triterpenes, such as betulinic acid, betulin, and lupenone, in the roots of A. amazonicus.[23] Betulinic acid has shown a wide range of biological activities, including leishmanicidal, trypanocidal and antiplasmodial.[24,25] Melaleucic acid is a rare triterpene acid, whose isolation, so far, has been reported mainly for Melaleuca species (myrtaceae),[16,26] A. amazonicus (rhamanaceae),[23] Anomospermum grandifolium 
(annonaceae)[27] and Heteropanax fragans (araliaceae).[28] Unlike betulinic acid, there have been no studies on their pharmacological activity.

The activity of the isolated compounds is shown in Table 2. All the triterpenes, with the exception of melaleucic acid, exhibited antiplasmodial activity against $P$. falciparum strains with $\mathrm{IC}_{50}$ values ranging from 5.6 to $80.30 \mu \mathrm{M}$. The most active compound was the naturally-occurring triterpene betulinic acid, and these results corroborate those described in the literature for this substance.[25,29] The results found

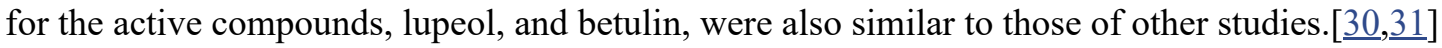

Functional groups present in the structures of the triterpenes can be used to explain the different values of activity found among the compounds,[25] and they can be used to explain the variation in $\mathrm{IC}_{50}$ values of the isolated triterpenes. Furthermore, the antimalarial activity of the betulinic acid, compared with other triterpenes, suggests that the presence of the $3-\beta$-hydroxyl and C-28 carboxyl groups is important for this result.[29 ]

The most active triterpene, betulinic acid, was quantified in the CRBAa extract by HPLC-PAD, and the results were compared with the $\mathrm{IC}_{50}$ values found for each extract [Table 1]. For the chromatographic analysis, experiments were carried out to optimize the mobile phase conditions in order to obtain the best separation and resolution between betulinic acid and other constituents of the extracts. The isocratic system with water: Acetonitrile $(30: 70, \mathrm{v} / \mathrm{v})$ resulted in the chromatograms of the extract and betulinic acid standard shown in Figure 1.

It was possible to identify betulinic acid in chloroform extract, with good separation within 20 min, under the conditions described above. The concentration of this triterpene in the root bark chloroform extract was $300.85 \mu \mathrm{g} / \mathrm{mL}$.

The hexane, ethanol, and aqueous extracts, which showed no significant antiplasmodial activity against both $P$. falciparum strains, were also analyzed by HPLC-PAD, and with the exception of the hexane extract $(32.12 \mu \mathrm{g} / \mathrm{mL}$ of betulinic acid), the other did not present any detectable amount of betulinic acid in their composition at the concentration studied and with the detector used. These results suggest that the amount of betulinic acid may be important for the antiplasmodial activity of the extract. Recently, Quan et al. (2013)[32] reported that betulinic acid can cause modifications of erythrocyte cholesterol-rich membrane rafts, reduce hepatic steatosis, and be used to prevent fatty liver disease. Since these membrane rafts are important for the entry of the malaria parasite to the host cells, according to our results, the extracts of $A$. amazonicus enriched with betulinic acid could be promising for preventing and treating malaria, especially taking into account that $P$. falciparum does not enter erythrocyte that is preloaded with this terpenoid.

As previously mentioned, A. amazonicus is used in folk medicine of the Amazon region to prevent malaria and treat the symptoms of this disease. In this context, the results of this work demonstrated some important facts, such as the blood stage antimalarial activity detected in chloroform extract and the isolation of active triterpenes. Furthermore, the phytochemical methodology adopted in this work enabled the highest activity to be concentrated in the chloroform extract, which led to an association between the constituents of this plant with its antimalarial activity.

In conclusion, this study provides biological evidence that $A$. amazonicus has important antiplasmodial activity, due to the presence of pentacyclic triterpenes. The results demonstrated that using different extraction solvents of varying polarities was a good strategy for selecting chemical classes with identifiable components, unlike the use of a crude extract. Two extracts of the root bark exhibited moderate activity against the liver stage of $P$. berghei, with the chloroform of the root bark being the most active. The hexane and chloroform extracts of the root bark, studied for their activities against erythrocyte stage of P. falciparum in this work, were analyzed by HPLC-PAD, showing that the highest amount of betulinic acid was in the chloroform extract, which also presented the highest bioactivity. Based on these premises, it is clear that this is a complex and important plant species, and further studies are strongly recommended, particularly regarding their action in the prevention of malaria. 
The authors are grateful to CNPq, Fapeam (PPP and PIPT projects), RIDES Malaria CPLP and IFS, Stockholm, Sweden (project number AF/18880) and OPCW, Hages, Netherlands for financial supports. JRAS and VER thank CAPES-FCT (project number 204/08). DFMC thanks FAPEAM and CAPES fellowships.

\section{Footnotes} Go to:

\section{Source of Support: Nil}

Conflict of Interest: None declared.

1. WHO. World Health Organization 2011. World Malaria Report. 2011. [Last accessed on 2014 Mar 10]. Available from: http://www.who.int/malaria/world_malaria_report_2011.

2. WHO. World Health Organization. 2012. [Last accessed 2014 May 10]. Available from: http://www.who.int/mediacentre/factsheets/fs094/en/

3. Fairhurst RM, Nayyar GM, Breman JG, Hallett R, Vennerstrom JL, Duong S, et al. Artemisinin-resistant malaria: Research challenges, opportunities, and public health implications. Am J Trop Med Hyg. 2012;87:231-41. [PMCID: PMC3414557] [PubMed: 22855752]

4. Noedl H, Se Y, Schaecher K, Smith BL, Socheat D, Fukuda MM, et al. Evidence of artemisinin-resistant malaria in western Cambodia. N Engl J Med. 2008;359:2619-20. [PubMed: 19064625]

5. Silva JR, Ramos Ade S, Machado M, de Moura DF, Neto Z, Canto-Cavalheiro MM, et al. A review of antimalarial plants used in traditional medicine in communities in Portuguese-speaking countries: Brazil, Mozambique, Cape Verde, Guinea-Bissau, São Tomé and Príncipe and Angola. Mem Inst Oswaldo Cruz. 2011;106(Suppl 1):142-58. [PubMed: 21881769]

6. Amaral AC, Pereira JL, Moura DF, Carvalho JR, Ohana DT, Echevarria A, et al. Uptated studies on Ampelozizyphus amazonicus, a medicinal plant used in the Amazonian Region. Pharmacogn Rev. 2008;2:308-16.

7. Oliveira DR, Costa AL, Leitão GG, Castro NG, Santos JP, Leitão SG. Ethnopharmacology study of Saracuramirá (Ampelozizyphus amazonicus Ducke) in the "Quilombola" communities of Oriximiná, Pará State, Brazil. Acta Amazon. 2011;41:383-92.

8. Krettli AU, Andrade-Neto VF, Brandão MG, Ferrari WM. The search for new antimalarial drugs from plants used to treat fever and malaria or plants ramdomly selected: A review. Mem Inst Oswaldo Cruz. 2001;96:1033-42. [PubMed: 11784919]

9. Rodrigues E. Plants and animals utilized as medicines in the Jaú National Park (JNP), Brazilian Amazon. Phytother Res. 2006;20:378-91. [PubMed: 16619367]

10. Rosas LV, Cordeiro MS, Campos FR, Nascimento SK, Januário AH, França SC, et al. In vitro evaluation of the cytotoxic and trypanocidal activities of Ampelozizyphus amazonicus (Rhamnaceae) Braz J Med Biol Res. 2007;40:663-70. [PubMed: 17464428]

11. Andrade-Neto VF, Brandão MG, Nogueira F, Rosário VE, Krettli AU. Ampelozyziphus amazonicus Ducke (Rhamnaceae), a medicinal plant used to prevent malaria in the Amazon Region, hampers the development of Plasmodium berghei sporozoites. Int J Parasitol. 2008;38:1505-11. [PubMed: 18599059]

12. Diniz LR, Santana PC, Ribeiro AP, Portella VG, Pacheco LF, Meyer NB, et al. Effect of triterpene saponins from roots of Ampelozizyphus amazonicus Ducke on diuresis in rats. J Ethnopharmacol. 2009;123:275-9. [PubMed: 19429372]

13. Reynolds WF, Mclan S, Poplawski J. Total assignment of $13 \mathrm{C}$ and $1 \mathrm{H}$ spectra of isomeric triterpenol derivatives by 2D NMR. Tetrahedron. 1986;42:3419-28.

14. Sharma PP, Roy B, Anurag RK, Gupta D. Pentacyclic triterpenoids from Betula utilis and Hyptis suaveolens. Int J Pharm Tech Res. 2010;2:1532-58. 
15. Tinto WF, Blair LC, Alli A. Lupane triterpenoids of Salacia cordata. J Nat Prod. 1992;55:395-8.

16. Chopra CS, Cou AR, Teieiberg KJ, White DE, Arthur HR. Triterpene compounds VII. The constitution of melaleucic acid. Tetrahedron. 1965;21:1529-36.

17. Mahato SB, Kundu AP. ${ }^{13} \mathrm{C}$ NMR spectra of pentacyclic triterpenoids-a compilation and some salient features. Phytochemistry. 1994;37:1517-75.

18. Do Céu de Madureira M, Paula Martins A, Gomes M, Paiva J, Proença da Cunha A, do Rosário V. Antimalarial activity of medicinal plants used in traditional medicine in S. Tomé and Príncipe islands. J Ethnopharmacol. 2002;81:23-9. [PubMed: 12020924]

19. Trager W, Jensen JB. Human malaria parasites in continuous culture. Science. 1976;193:673-5. [PubMed: 781840]

20. Smilkstein M, Sriwilaijaroen N, Kelly JX, Wilairat P, Riscoe M. Simple and inexpensive fluorescencebased technique for high-throughput antimalarial drug screening. Antimicrob Agents Chemother.

2004;48:1803-6. [PMCID: PMC400546] [PubMed: 15105138]

21. Noedl H, Wernsdorfer WH, Krudsood S, Wilairatana P, Viriyavejakul P, Kollaritsch H, et al. In vivo-in vitro model for the assessment of clinically relevant antimalarial cross-resistance. Am J Trop Med Hyg. 2001;65:696-9. [PubMed: 11791959]

22. WHO. World Health Organization. 2007. [Last accessed 2015 Apr 02]. Available from: http://whqlibdoc.who.int/publications/2007/9789241595155 eng.pdf.

23. Brandao MG, Lacaille-Dubois MA, Teixera MA, Wagner H. Triterpene saponins from the roots of Ampelozizyphus amazonicus. Phytochemistry. 1992;31:352-4. [PubMed: 1367885]

24. Yogeeswari P, Sriram D. Betulinic acid and its derivatives: A review on their biological properties. Curr Med Chem. 2005;12:657-66. [PubMed: 15790304]

25. Domínguez-Carmona DB, Escalante-Erosa F, García-Sosa K, Ruiz-Pinell G, Gutierrez-Yapu D, ChanBacab MJ, et al. Antiprotozoal activity of betulinic acid derivatives. Phytomedicine. 2010;17:379-82. [PubMed: 19748254]

26. Vieira TR, Barbosa LC, Maltha CR, Paula VF, Nascimento EA. Constituintes químicos de Melaleuca alternifólia (Myytaceae) Quim Nova. 2004;27:536-9.

27. Plaza A, Cinco M, Tubaro A, Pizza C, Piacente S. New triterpene glycosides from the stems of Anomospermum grandifolium. J Nat Prod. 2003;66:1606-10. [PubMed: 14695805]

28. Zhao S, Huang Z, Gao J. Lupane-type triterpenoids from the leaves of Heteropanax fragrans. Bull Korean Chem Soc. 2011;32:1368-70.

29. Steele JC, Warhurst DC, Kirby GC, Simmonds MS. In vitro and in vivo evaluation of betulinic acid as an antimalarial. Phytother Res. 1999;13:115-9. [PubMed: 10190183]

30. Ziegler HL, Franzyk H, Sairafianpour M, Tabatabai M, Tehrani MD, Bagherzadeh K, et al. Erythrocyte membrane modifying agents and the inhibition of Plasmodium falciparum growth: Structure-activity relationships for betulinic acid analogues. Bioorg Med Chem. 2004;12:119-27. [PubMed: 14697777]

31. Fotie J, Bohle DS, Leimanis ML, Georges E, Rukunga G, Nkengfack AE. Lupeol long-chain fatty acid esters with antimalarial activity from Holarrhena floribunda. J Nat Prod. 2006;69:62-7.

[PubMed: 16441070]

32. Quan HY, Kim do Y, Kim SJ, Jo HK, Kim GW, Chung SH. Betulinic acid alleviates non-alcoholic fatty liver by inhibiting SREBP1 activity via the AMPK-mTOR-SREBP signaling pathway. Biochem Pharmacol. 2013;85:1330-40. [PubMed: 23435355] 


\section{Table 1}

\begin{tabular}{|c|c|c|c|c|c|c|c|}
\hline \multirow[t]{3}{*}{ Code } & \multirow[t]{3}{*}{ Extract-plant part } & \multicolumn{4}{|c|}{$\mathrm{IC}_{50}(\mu \mathrm{g} / \mathrm{mL})$} & \multicolumn{2}{|c|}{ SI } \\
\hline & & \multirow{2}{*}{$\begin{array}{l}\text { Cytotoxicity } \\
\text { (HepG2 cells) }\end{array}$} & \multirow{2}{*}{$\begin{array}{l}\text { Schizonticide } \\
\text { activity }\end{array}$} & \multicolumn{2}{|c|}{ Plasmodium falciparum } & \multirow[t]{2}{*}{ HepG2/3D7 } & \multirow[t]{2}{*}{ HepG2/Dd2 } \\
\hline & & & & 3D7 & Dd2 & & \\
\hline CRBAa & Chloroform-root bark & $64.52 \pm 2.16$ & $30.1 \pm 1.59$ & $13.79 \pm 3.29$ & $14.63 \pm 7.09$ & 4.68 & 4.41 \\
\hline ERBAa & Ethanol-root bark & $93.44 \pm 2.58$ & $82.00 \pm 1.75$ & $54.08 \pm 1.70$ & $68.64 \pm 4.16$ & 1.72 & 1.36 \\
\hline AqRBAa & Aqueous-root bark & $17.50 \pm 4.16$ & $39.9 \pm 2.65$ & $66.98 \pm 11.88$ & $78.26 \pm 1.92$ & 0.26 & 0.22 \\
\hline
\end{tabular}

$\mathrm{IC}_{50}$ : Inhibitory concentration 50\%; 3D7: Chloroquine-sensitive; Dd2: Chloroquine-resistant strains; HepG2: Human liver hepatocellular carcinoma cell line; SI: Selectivity index

Biological activities of the extracts from Ampelozizyphus amazonicus 
Table 2

\begin{tabular}{|c|c|c|}
\hline \multirow[t]{2}{*}{ Compound } & \multicolumn{2}{|c|}{ Plasmodium falciparum $\mathrm{IC}_{50}(\mu \mathrm{M})$} \\
\hline & $3 \mathrm{D} 7^{\mathrm{a}}$ & $\mathrm{Dd} 2^{\mathrm{b}}$ \\
\hline Lupeol & $80.30 \pm 2.15$ & $54.22 \pm 0.31$ \\
\hline Betulinic acid & $5.60 \pm 1.51$ & $8.23 \pm 0.69$ \\
\hline Betulin & $17.08 \pm 3.20$ & $14.22 \pm 0.03$ \\
\hline Melaleucic acid & $508.74 \pm 5.02$ & $710.10 \pm 16.97$ \\
\hline
\end{tabular}

Antiplasmodial activity of isolated triterpenes from Ampelozizyphus amazonicus 
Figure 1

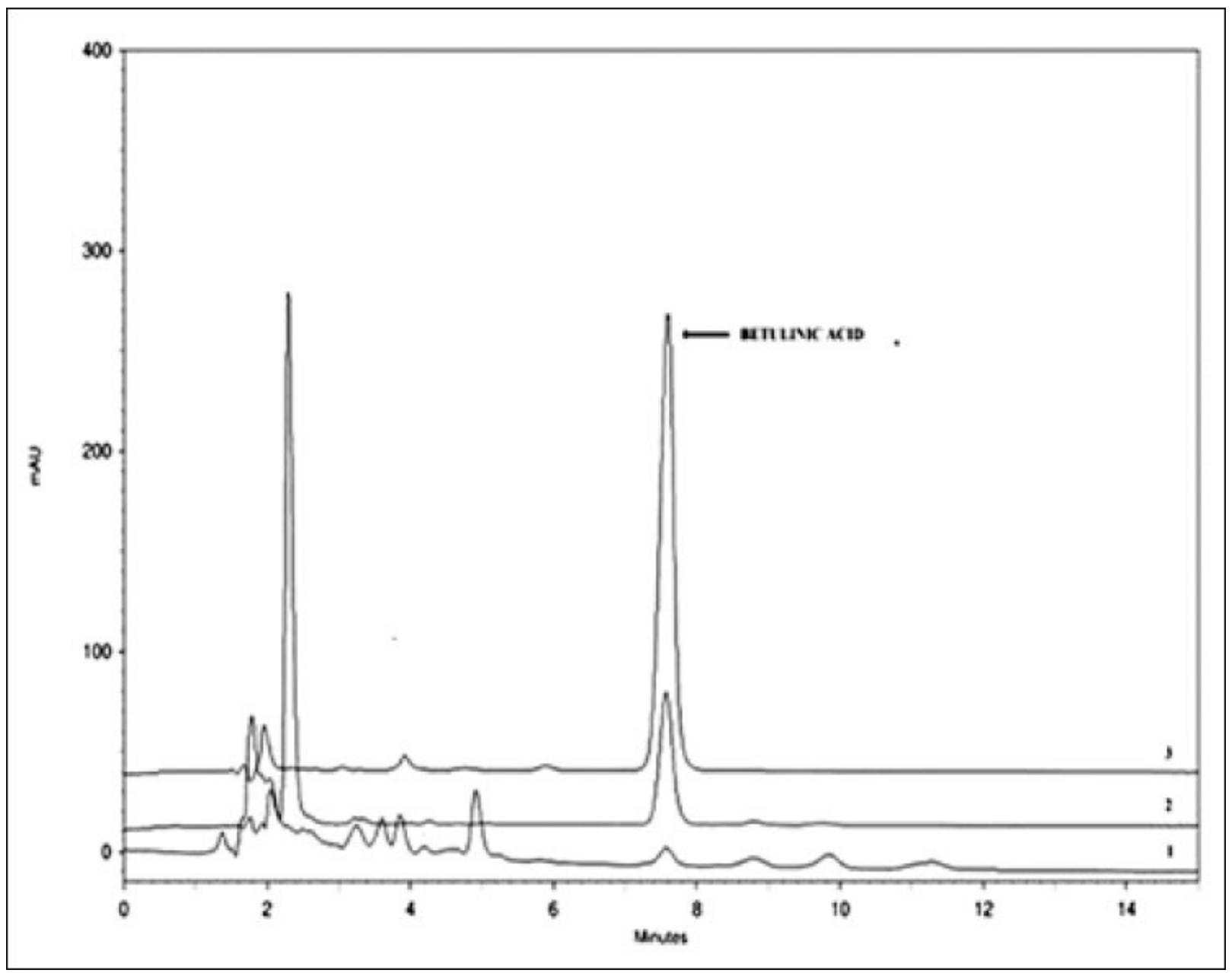

Open in a separate window

Comparative high-performance liquid chromatography chromatograms at $210 \mathrm{~nm}$ for (1) HRBAa (2) CRBAa and (3) standard betulinic acid in the most active extracts

Articles from Pharmacognosy Magazine are provided here courtesy of Wolters Kluwer -- Medknow Publications 